\title{
Microstructure and Wear Resistance of Ti6Al4V Surfaces Processed by Pulsed Laser
}

\author{
Shixuan Chen ${ }^{1 \mathrm{a}}$, Ahmet D. Usta ${ }^{\mathrm{b}}$, and Melih Eriten ${ }^{\mathrm{b}}$ \\ ${ }^{a}$ Department of Materials Science and Engineering, \\ ${ }^{\mathrm{b}}$ Department of Mechanical Engineering, \\ University of Wisconsin - Madison \\ 1513 University Avenue, Madison, WI 53706, USA
}

\begin{abstract}
When pulsed laser beams deposit spatially and temporally localized power on the metallic surfaces, microstructure and mechanical properties could change significantly. During and after each pulse, the exposed surface experiences a cycle of thermal processes involving extremely high heating and cooling rates, which consequently cause significant microstructure evolution. Changes in mechanical strength follow such microstructural changes. In this work, the influence of pulsed laser processing (PLP) on microstructural evolution, resulting hardness and wear resistance of Ti6Al4V surfaces is investigated. Average pulse power is varied from surface heating to melting regimes in processing. A $2 \mathrm{D}$ axisymmetric finite element model of a single pulse is utilized to obtain the heating and cooling histories, and a phase transformation mapping procedure is used to obtain the microstructural evolution. Melting (MZ) and heat affected zones (HAZ) observed at the cross sections of the processed surfaces are found to correlate with the predicted temperature field. The resulting phases in those zones are predominantly martensitic $\alpha^{\prime}$ and $\alpha$ phase; higher laser power produces thicker martensitic $\alpha^{\prime}$ surface layers several microns into the processed surface. Nanoindentation, nano/microscale and mesoscale wear tests are then applied to the processed surfaces to identify the effects of microstructure on hardness and wear resistance. The surface processed by higher laser power shows higher hardness and wear resistance compared to the surface processed by low power laser. The hardness and wear resistance of the surface processed by low power laser shows no obvious change from substrate material. Mixture of hard martensitic surface layer and underlying ductile substrate resulting from PLP facilitate superior resistance to abrasive and partly low cycle fatigue wear.
\end{abstract}

\footnotetext{
${ }^{1}$ Corresponding author; email:schen376@wisc.edu; tel: +1 (608) 2078029
} 
Key words: Pulsed laser processing; phase transformation; wear resistance; hardness

\section{Introduction}

Titanium alloys are widely used in aerospace, automotive, chemical and prosthetics industries due to their high strength-to-weight ratio, excellent corrosion resistance and outstanding biocompatibility [1-6]. However, relatively poor tribological properties such as low wear resistance and high friction coefficients [7] limit their utilization in especially biomedical applications [1-3,5].

A series of surface modification techniques has been applied to improve the surface and wear properties of titanium and titanium alloys [1-3,6,8-10]. Our focus will be on laser-based techniques. Traditional continuous laser processing of Ti6Al4V creates processed layer up to $1 \mathrm{~mm}$ thickness with brittle martensite as the dominant phase [11-14]. However, thick brittle surface layers exhibit increased fatigueinduced fractures and wear under cyclic loading [15]. Nano regime laser processing, such as free electron laser nitriding, is also applied to surface alloying [16,17]. The roughness after processing could reach 1.24 to $3.23 \mu \mathrm{m}$ by generating a coating layer, with a thickness of 5 to $70 \mu \mathrm{m}$. However, undesirable cracks form as the pulse duration varies [17]. In the past decade, pulsed laser processing (PLP) has been applied to improve metal surface roughness. Perry, et al. [18] has demonstrated that PLP by neodymium-doped yttium aluminum garnet (Nd:YAG) laser reduces the surface roughness of micro-end milled Ti6Al4V from $0.206 \mu \mathrm{m}$ to $0.070 \mu \mathrm{m}$. During PLP, laser heats a small region confined to the vicinity of the exposed surface, and the thermal energy is absorbed and transferred to lattice phonons by collision [19]. When the thermal energy is sufficient for melting, the molten processed zone is smoothened by surface tension [20]. The wear and friction on a surface, in particular abrasive wear, will be reduced with decreasing roughness [21,22], and thus, PLP has a potential to improve the wear behavior of the processed region. Similar to continuous laser processing, the thermal treatment and temperature history generated by PLP will change the microstructure and mechanical properties [23]. By changing the laser parameters, it is possible to control the phase fractions and distributions as well as surface roughness over much thinner (several microns) surface layers than the layers processed by continuous lasers, without 
having to introduce other elements. Therefore, combination of a smooth thin brittle martensitic layer and ductile underlying bulk material could be obtained to improve wear resistance [15]. However, microstructural characterization of the shallow MZ and HAZ obtained by PLP is challenging since common characterization tools such as X-ray diffraction measurements (XRD) fail to deliver dependable results for small surface patches [23]. In addition, during PLP short laser bursts with high intensity heats a small surface volume, and the rest of the part behaves as a global heat sink, which leads to extremely rapid heating and cooling rates that are difficult to be measured by the current state-of-the-art thermal monitoring. Nevertheless, laser-induced microstructural changes are investigated on different material systems [24][25-28]. The results show that the processed area is divided into three regions: a laser MZ, a HAZ and unaffected base material [25,26,28]; the hardness is improved after laser processing [24,27]. In these works, the laser pulse durations are longer ( milli-seconds) than in the PLP; and pulse radii are several millimeters. In our work, the pulse durations will be a few microseconds while the beam diameter will be around $30 \mu \mathrm{m}$. Those processing parameters are more suitable for polishing smaller parts and components. To investigate the thermal history and microstructural evolution for PLP with those processing parameters, we will employ a numerical transformation and composition mapping approach. Similar approach was already shown to work for continuous laser processed Ti6A14V samples. In particular, Fan, et al. [11] model the phase transformations during heating and cooling cycles of continuous laser processing, and predict and verify the final phase composition in the processed Ti6Al4V samples. The phase transformation models are based on the thermal cycles and the kinetic models of phase transformation. The HAZ and mechanical properties of the processed surface with the predicted microstructure compare well with the experiment results. In line with this approach, we will relate the temperature variations during a single laser pulse to microstructural evolution and final phase composition. As done elsewhere [29], a 2D axisymmetric finite element model of transient heat transfer will be utilized to obtain the temperature changes due to a single laser pulse. Throughout the pulse duration, the rapid heating occurs and transforms the original two-phase $(\alpha-\beta)$ composition to $\beta$-dominant one. Subsequently rapid cooling is achieved mostly by the thermal diffusion to the unaffected bulk 
material. During the cooling cycle, $\beta$ phase decomposes into martensitic or secondary $\alpha$ phases depending on the cooling rates. Since the pulses are highly localized and short in duration, extremely high temperature gradients, and a wide range of heating and cooling rates are observed in PLP. Johnson-MehlAvrami (JMA) equations can be modified to model the phase transformations during those isothermal conditions [30]. Therefore, the spatial variation of phases and resulting phase composition will have a prominent influence on mechanical properties of the PLPed surfaces. Different phases in Ti6Al4V are already shown to provide different hardness, toughness, wear resistance and fatigue strength [31-35].

Characterization of changes in mechanical properties of PLPed surfaces requires nano/microscale and mesoscale tests due to thin processed zones. In this work, we will conduct nanoindentation, nano/microscale and mesoscale abrasive wear testing on the PLPed Ti6Al4V samples, and relate the mechanical properties to predicted phase compositions. The details of the materials, processing, experiments, heat transfer model, and phase composition mapping procedure are given in Sections 2 and 3. Section 4 lists our findings on the predicted phase compositions and the processed layers verified by scanning electron microscopy, and the corresponding nanohardness, scratch and wear properties.

\section{Material and methods}

\subsection{Base Material}

Ti6A14V, a two-phase $(\alpha+\beta)$ commercial titanium alloy, is studied in this work. X-ray diffraction (XRD) characterization is applied on the well-polished base material surface to identify the initial phases and the corresponding volume fractions by Bruker D8 Discover diffractometer; the XRD pattern is shown in Fig. 1. The red base line is identified for $2 \theta>38^{\circ}$ and is subtracted as background. The peaks of $\alpha(101)$ and $\beta$ (110) are selected to calculate the volume fractions by Eq. (1) [11],

$I_{\beta} / I_{\alpha}=A_{0} f_{\beta} / f_{\alpha}=\left(A_{0}\left(1-f_{\alpha}\right)\right) / f_{\alpha}$

where $I_{\alpha}$ and $I_{\beta}$ are the integrated intensities of $\alpha$ and $\beta$ phases, respectively; and $f_{\alpha}$ and $f_{\beta}$ are the volume fractions of $\alpha$ and $\beta$, respectively. The coefficient $A_{0}$ attains the value of 1.672 for Ti6Al4V [11], and $I_{\alpha}$ and $I_{\beta}$ are estimated as 390.44 and 67.1, respectively using the XRD peaks. Substituting those 
values in Eq. (1) yields $90.7 \%$ and $9.3 \%$ respectively for the volume fractions of $\alpha$ and $\beta$ phases. The initial surface is micro-end milled, which might cause preferable orientations of these two phases. Note that this anisotropy might cause deviations in the volume fractions measured by assuming isotropy. According to the literature, the volume fractions of $\alpha$ and $\beta$ phases are reported as $88 \%$ and $12 \%$, respectively [36,37]. This range is similar to the measured results, and hence, isotropy assumption in the estimation of phase fractions is reasonable.

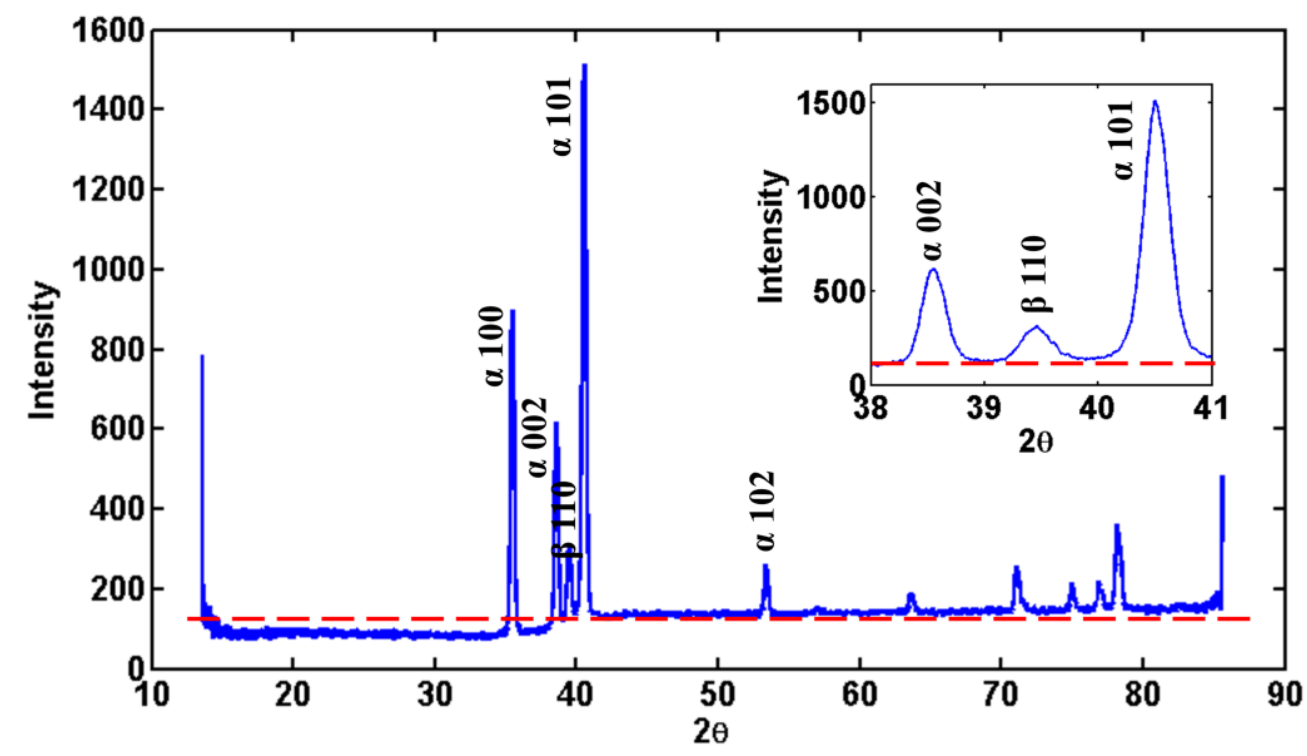

Fig. 1. Intensity versus diffraction angle $2 \theta$ in degrees in XRD characterization pattern of a mechanically polished Ti6Al4V sample. The red base line is identified for $2 \theta>38^{\circ}$ and is subtracted as background. The peaks of $\alpha(101)$ and $\beta$ (110), shown as the close-up figure are used to calculate initial volume fractions.

\subsection{Pulsed Laser Processing}

The titanium specimen is in the shape of a rectangular prism with the dimension of $6 \times 11 \times 3 \mathrm{~mm}$. A 1070 nm fiber laser (SPI Lasers, Model: SP-200C-W-S6-A-B) with two levels of average laser power settings, $3.99 \mathrm{~W}$ and $1.71 \mathrm{~W}$ are selected to process the surface resulting in two regions of different flow regimes. For Ti6Al4V, there are two main flow regimes, thermocapillary regime and capillary regime [20]. In thermocapillary regime, surface tension gradient is dominant during the flow; in capillary regime, surface tension gradient is neglected comparing with viscous forces and stationary capillary waves controlling the 
flow [29]. Region 1 polished with $3.99 \mathrm{~W}$ laser is between thermocapillary regime and ablation; Region 2 polished with $1.71 \mathrm{~W}$ laser is in thermocapillary regime but nearly in capillary regime [20]. Laser polishing is carried out over 0.8-mm wide strips. For both regions, the laser beam diameter, pulsing frequency, duty cycle and scanning velocity are set to $30 \mu \mathrm{m}, 40 \mathrm{kHz}, 20 \%$ and $200 \mathrm{~mm} / \mathrm{s}$, respectively. The full-width-half-maximum pulse duration is $1.56 \mu \mathrm{s}$. All the experiments are completed in argon atmosphere, so there is no oxidation or impurity introduced into the surface while processing.

\subsection{Nanoindentation and Scanning Wear}

TI 950 Triboindenter by Hysitron is used in nanoindentation and scanning wear tests. For testing the hardness, a Berkovich diamond probe with a tip radius of approximately $100 \mathrm{~nm}$ is applied on the cross section of PLPed area at different depth levels below the top surface, from $2 \mu \mathrm{m}$ to $33 \mu \mathrm{m}$. The penetration depth is set to $200 \mathrm{~nm}$ for each indent, and the loading/unloading rate is $20 \mathrm{~nm} / \mathrm{s}$ constantly. Oliver-Pharr (OP) method [38] is applied to analyze the hardness as Eq. (2)

$H=P_{\max } / A$

where $A$ is the projected area, $P_{\max }$ is the maximum normal load. The area function for Berkovich probe is

$A=24.5 h^{2}$

where $h$ is the penetration depth.

Scanning wear tests are conducted on both top surfaces and Region 1 cross section with TI 950 Triboindenter by Hysitron. A NorthStar cube corner diamond probe with a tip radius of $40 \mathrm{~nm}$ is used in nanoscratch test. For the tests on top surfaces, the scratched size is $20 \times 20 \mu \mathrm{m}$, and the normal load is 500 $\mu \mathrm{N}$. A full scan consisting of 256 scanning lines is accomplished in one single pass. 1-pass and 10-pass tests are performed on both regions; on Region 1, 50-pass and 100-pass wear tests are also studied. Moreover, a 10-pass test on Region 1 cross section starting from the top surface with an area of $10 \times 10 \mu \mathrm{m}$ is performed as Fig. 2 shows, using the same experimental settings as the tests on top surfaces. A slope is generated on the cross section during mechanical polishing. Before analyzing the result, the slope should 
be eliminated. A line parallel to the top surface is selected to be the reference, subtracting the relative height before scratching test of each point to the reference line can lead to a flat cross section without significant slope. After each scanning wear test, a scanning probe microscopy (SPM) measurement is conducted to obtain the complete topography of the tested area. The SPM imaging load, size and frequency are $2 \mu \mathrm{N}, 60 \mathrm{x} 60 \mu \mathrm{m}$ and $1 \mathrm{~Hz}$, respectively.

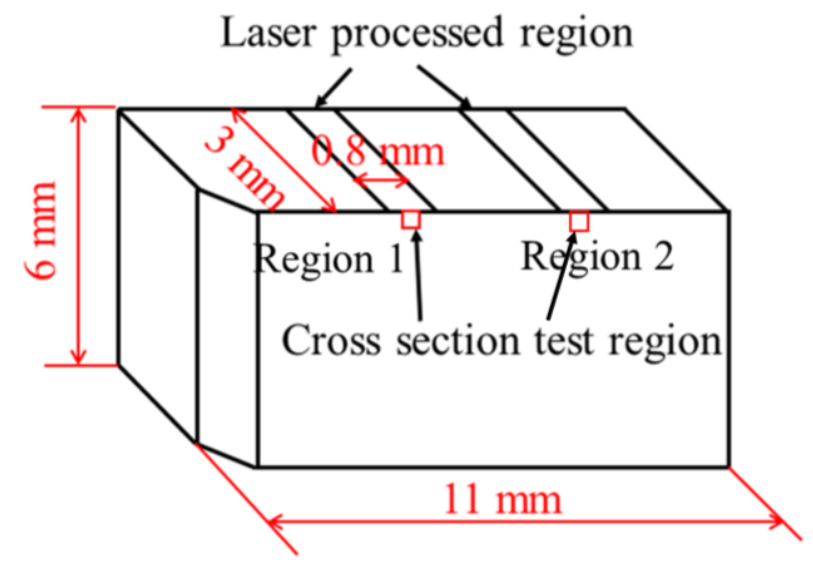

Fig. 2. Ti6Al4V Sample geometry showing laser processed regions. Nano/micro and mesoscale wear tests are performed on laser processed regions; the hardness tests and SEM characterizations are performed on the cross sections; a 10-pass nanoscale wear test is also performed on the cross section of Region 1.

\subsection{Mesoscale Wear Tests}

A nano-tribometer, NTR2 by Anton-Paar GmbH is utilized in the mesoscale wear experiments. Two different normal loads, $100 \mathrm{mN}$ and $1 \mathrm{~N}$, and 4 trials per normal load are applied on each region. The radius of the sphero-conical diamond probe that used for this test is $100 \mu \mathrm{m}$; the half angle is $45^{\circ}$. Each single experiment consists of 2000 cycles running at $500 \mu \mathrm{m} / \mathrm{s}$ of sliding speed. The full amplitude of reciprocation is set to be $250 \mu \mathrm{m}$. Specimens on a piezo-stage are made to reciprocate back and forth against the tip. The resulting horizontal and vertical deflections of the cantilever are measured by capacitive sensors. These deflections are converted into normal and tangential force by using the precalibrated values of the linear stiffness values in the two orthogonal directions respectively. The cantilever is mounted on a piezo-stage working in the vertical direction which moves the cantilever system up/down during an experiment to keep normal force constant against scratch and effects from 
surface topography. The vertical position of the cantilever at its support is sensed at $20 \mathrm{~nm}$ of resolution and fed back to the controller by an LVDT system. This value is the sum of tip deflection and penetration into specimen. Tip deflection is measured by capacitive sensors and subtracted from cantilever position to calculate penetration depth in indentation mode.

\subsection{Scanning electron microscope (SEM)}

The sample is characterized with Leo 1530 FESEM/EDS before and after PLP on the cross sections right below the center of laser processed strips, as Fig. 2 shows. The sample is etched by etchant (70\% Nitric acid $6 \mathrm{ml}+50 \%$ Hydrofluoric acid $2 \mathrm{ml}+$ distilled water $92 \mathrm{ml}$ ) for 50 s before characterization

\section{Theory/calculation}

\subsection{Finite Element Model}

The temperature field and history of a single pulse is obtained with a finite element model (FEM) as in Ma, et al with COMSOL [29,39]. The 2D axisymmetric model with a width of $120 \mu \mathrm{m}$ and a height of 90 $\mu \mathrm{m}$ is divided into 2700 quadrilateral meshes with the size of $2 \times 2 \mu \mathrm{m}$. The material is simplified to be homogeneous and isotropic.

The governing equation of heat transfer includes conduction and advection, which is

$\rho c_{p}{ }^{\prime}\left[\frac{\partial T}{\partial t}+\nabla \cdot(\vec{u} T)\right]-\nabla \cdot(k \nabla T)=0$

where $\rho$ is the density, $k$ is the thermal conductivity, $c_{p}{ }^{\prime}$ is specific heat, $\vec{u}$ is fluid flow velocity, $T$ is temperature and $t$ is time. The density is $3886 \mathrm{~kg} / \mathrm{m}^{3}$ [40] ; the thermal conductivity and specific heat are temperature dependent, given in the Appendix. Initially the temperature is set to be room temperature, which is $298.15 \mathrm{~K}$.

The boundary condition of the heated surface is

$-k \nabla T=\alpha \vec{q}$

where $\alpha$ is the absorption rate which is 0.5 [29] for Ti6Al4V; and $\vec{q}$ is the heat flux which is a Gaussian distribution flux in this case. The absorbed Gaussian distribution flux is expressed by 
$\alpha \vec{q}=P_{a b s} \exp \left(-2 \frac{\mathrm{r}^{2}}{\mathrm{R}^{2}}\right)$ when $\mathrm{t}<t_{\text {pulse duration }}$

where $P_{a b s}$ is the absorbed power, $R$ is the radius of laser spot and $\mathrm{r}$ is distance between the calculated location and the beam center. $P_{a b s}$ is defined as

$P_{a b s}=P_{a v g} /(A \cdot D C)$

where $P_{a v g}$ is the average power, $A$ is the laser spot area and $D C$ is the duty cycle.

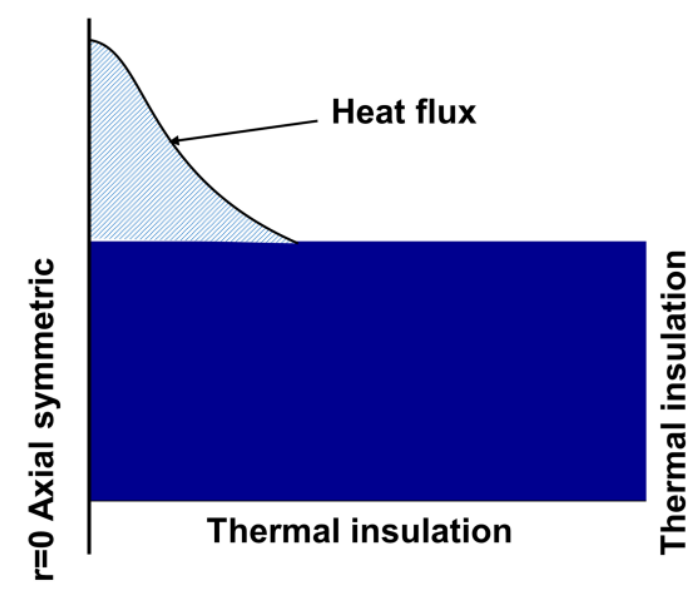

Fig. 3. Axisymmetric heat transfer model of pulsed laser processing of Ti6Al4V. The energy input of a single laser pulse is modeled as a Gaussian heat flux centered at $r=0$ on the surface for the pulse duration.

The laser center appears at $\mathrm{r}=0$ and an axial symmetric boundary is fixed here. The other two surfaces away from the heat source are thermal insulated.

\subsection{Phase Composition Mapping}

The phase composition is predicted by comparing the thermal history obtained via the finite element (FE) simulations to the critical cooling rate and transus temperature, shown in the continuous cooling diagram of Ti6Al4V, as Fig. 4. Comparing the maximum temperature of each node with the $\beta$ transus temperature, we determine the region with microstructure changes; and then the cooling rate at a particular node is compared to the critical cooling rate to decide which phase results. The transformation during heating starts when the temperature exceeds the initial temperature and ends at the end of a single pulse duration. The transformation during cooling starts at the end of a single pulse and lasts until the subsequent laser 
pulse. The volume fractions after heating and cooling can be identified by JMA equations according to the transition time obtained from the FE simulations. Similar approach was employed elsewhere [30].

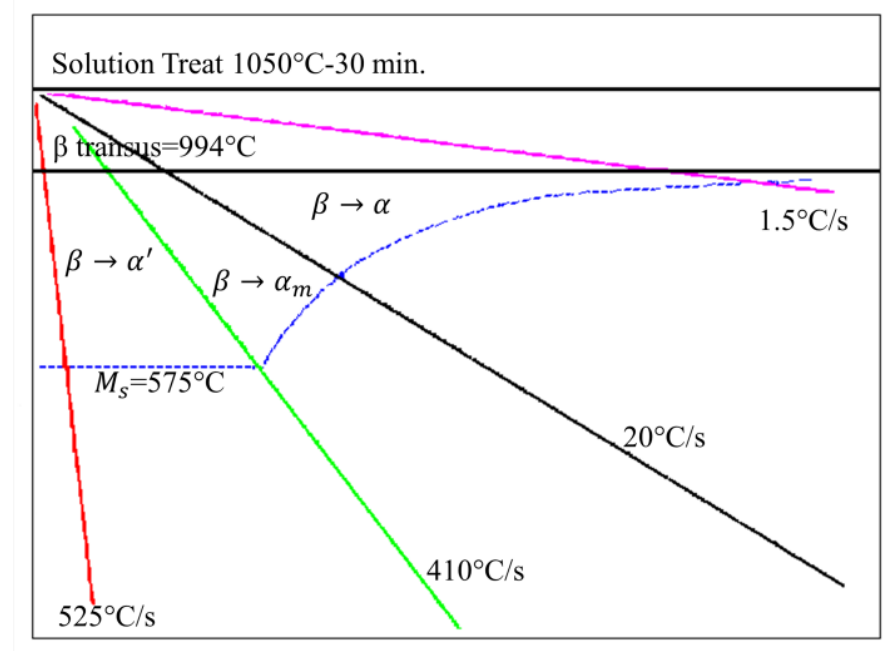

Fig. 4. Continuous cooling diagram of Ti6Al4V (reproduced after [41,42]).

The laser process of one pulse is divided into two periods, heating step and cooling step, which are separated when the temperature reaches maximum. During heating, $\alpha$ phase starts to transform into $\beta$ phase at a starting temperature $T_{\text {start }}$, which is around $930 \mathrm{~K}$ [43]. The procedure is modeled as done elsewhere $[11,30,44-46]$ as

$f_{\alpha}(t)=\left(1-\exp \left[-(K t)^{n}\right]\right) f_{\alpha}^{i n i}$

Where $f_{\alpha}(t)$ is the volume fraction of $\alpha$ phase after heating for a duration of $t ; f_{\alpha}^{\text {ini }}$ is the initial volume fraction of $\alpha$ phase; $K$ is the reaction rate constant; $n$ is the Avrami index. Above the $\beta$ transus temperature, $1267 \mathrm{~K}$, we assume $100 \% \beta$ phase is achieved even if the heating duration is relatively short. During cooling, $\beta$ phase transforms into second $\alpha$ phase or martensitic $\alpha^{\prime}$. If the cooling rate is higher than the critical cooling rate of $410 \mathrm{~K} / \mathrm{s}, \beta$ phase transforms mostly into martensitic $\alpha^{\prime}$ and part of $\beta$ phase remains after transformation [36]. Independent of the cooling rate, the remaining $\beta$ fraction is reported as $9 \pm 2 \%$ in the literature [46]. The information of martensitic transformation at an extremely high cooling rate is limited, and hence, we assume that $10 \% \beta$ phase will remain after the fast cooling. We will revisit this assumption in the discussion of the results. If the cooling rate is below $410 \mathrm{~K} / \mathrm{s}$, diffusion-controlled 
nucleation occurs and $\beta$ phase transforms partially into secondary $\alpha$ phase. This evolution can be modeled by $[11,30,44-46]$.

$f_{\text {second } \alpha}(t)=\left(1-\exp \left[-(K t)^{n}\right]\right)\left(f_{\alpha}^{\text {ini }}-f_{\alpha}^{r e m}\right)$

where $f_{\alpha}^{r e m}$ is the volume fraction of $\alpha$ phase after heating, $t$ is the cooling time. According to Malinov [30], the reaction-rate constant $K$ and Avrami index $n$ are investigated at a temperature range of $1023 \mathrm{~K}$ to $1223 \mathrm{~K}$. Since the values have no significant fluctuation and the time duration for the pulsed laser is small (microseconds), we use the average values of $K$ and $n$ in the phase decomposition analysis. In particular, we assign $K$ values of 0.02686 and 0.03929 , and $n$ values of 1.3529 and 1.2 during heating and cooling, respectively.

\section{Results and Discussions}

\subsection{Predicted phase components}

The first step in predicting the phase decomposition is to obtain the temperature field and its evolution during a laser pulse. Fig. 5 shows the predicted temperature fields of Region 1 and 2 at the end of a single laser pulse $(\mathrm{t}=1.6 \mu \mathrm{s})$. Note that the laser power and thus the heat flux imposed on Region 1 is much higher than that on Region 2. Therefore, the maximum temperature predicted for Region 1 is nearly twice as much as the one predicted for Region 2. Maximum temperatures occur at the centerline of the pulse due to the Gaussian spatial profile of the beam power. As expected, the laser-induced thermal energy diffuses radial and normal to the processed surface, and creates MZ above melting temperature and HAZ above $\beta$ transus temperature. MZ and HAZ for Region 1 extend up to 4 and $9 \mu \mathrm{m}$ depths from the processed surface. In contrast, shallower depths are predicted for Region 2; namely almost 0 and $5 \mu \mathrm{m}$ depths for MZ and HAZ, respectively.

Next, the cooling rates of all nodes are estimated by numerical differentiation of temperature field with respect to time. At each spatial location, the maximum temperature reached determines whether $\beta$ transformation occurs, and the cooling rate determines whether martensitic or secondary $\alpha$ phase transformation occurs. The predicted phase components and volume fractions at the end of an entire cycle 
$(\mathrm{t}=25 \mu \mathrm{s})$ are shown in Fig. 6 . For both regions, the dominant resulting phase in the vicinity of the center of laser pulse is martensitic $\alpha^{\prime}(\sim 90 \%)$ with $10 \%$ remaining $\beta$ phase. Around those locations, the maximum temperature exceeds the $\beta$ transus temperature and $\alpha$ phase transforms completely into $\beta$ phase. Cooling rates estimated for the same zones are higher than the critical cooling rate of $410 \mathrm{~K} / \mathrm{s}$ without an exception, and thus martensitic transformation is inevitable and no second $\alpha$ phase forms at this location. This is mainly due to the short thermal cycles occurring during the laser processing. Using Rosenthal's solution for a moving point heat source [47], we can estimate the cooling rates by

$\frac{d T}{d t}=-2 \pi k\left(\frac{V}{P}\right) \Delta T^{2}$

where $k$ is the thermal conductivity, $6.7 \mathrm{~W} /(\mathrm{m} \cdot \mathrm{K})$ [48] for Ti6Al4V; $V$ is the scan velocity, $200 \mathrm{~mm} / \mathrm{s}$ for our laser beam; $P$ is the laser power, which is $3.99 \mathrm{~W}$ for Region 1 and $\Delta T$ is the range of temperature variation during cooling, which is assumed as the difference between the melting temperature and room temperature $(\sim 1000 \mathrm{~K})$. Substituting those values, we obtain extremely high cooling rates on the order of $10^{6} \mathrm{~K} / \mathrm{s}$ at the center of the pulse. Our FE simulations also yield comparable cooling rates on the order of $10^{7} \mathrm{~K} / \mathrm{s}$. Therefore, it is expected that the ultimate phase is mainly determined by the maximum temperature just after a single laser heating.
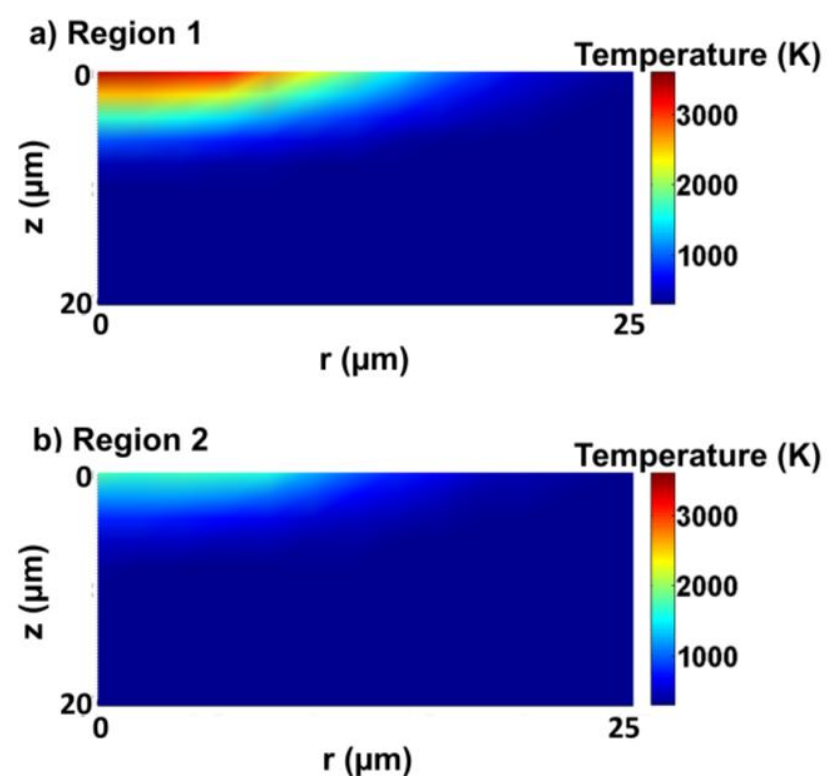
Fig. 5. Temperature field at $\mathrm{t}=1.6 \mu$ s immediately after the laser pulse on a) Region 1, and b) Region 2. As expected, the maximum temperature (3427 K for Region 1, $1790 \mathrm{~K}$ for Region 2) occurs at the laser center.

a) Region 1
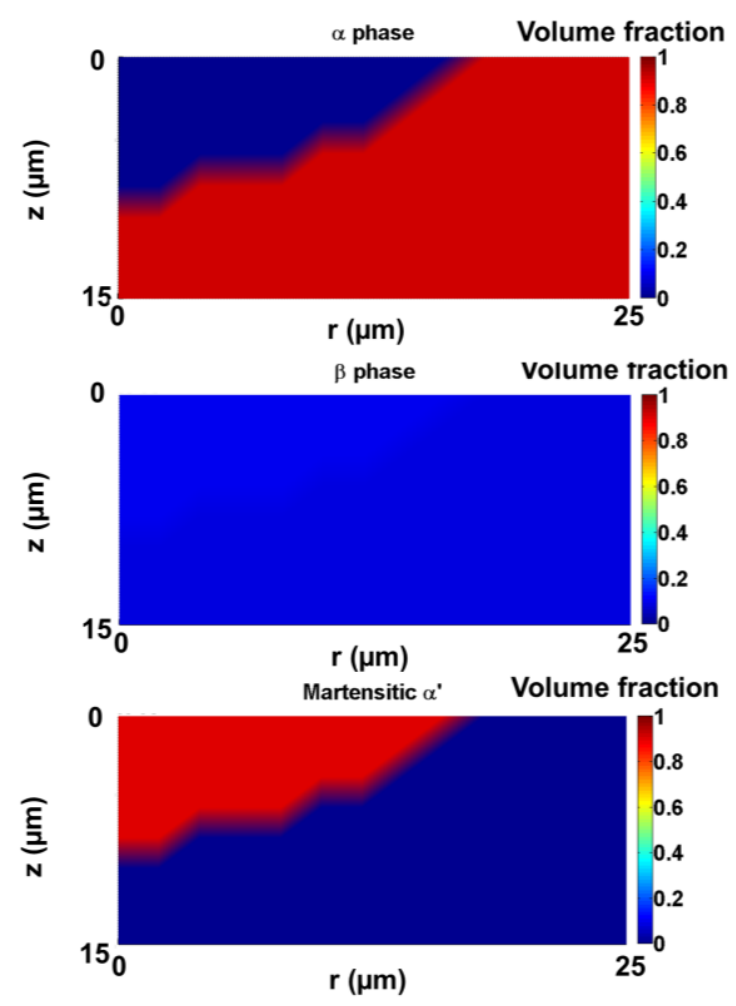

\section{b) Region 2}
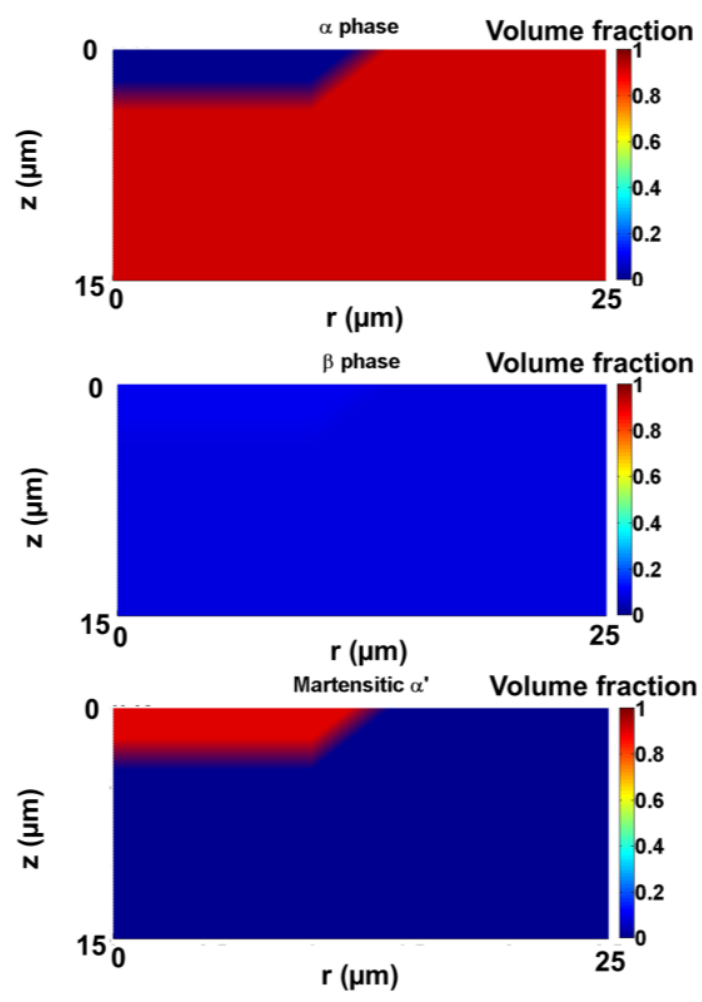

Fig. 6. Volume fraction maps of different phases on a) Region 1, and b) Region 2 after a single pulse cycle of $25 \mu$ s. The area undergoing martensitic transformation is much larger on Region 1 than in Region 2.

In accordance with this argument, the martensitic transformation ceases at a particular depth from the surface. The maximum temperature at this depth is approximately the beta transus temperature. Below this depth, $\alpha$ phase replaces martensitic $\alpha^{\prime}$ phase and dominates the remaining part of the sample. According to the prediction, there is no observable secondary $\alpha$ phase formed after phase transformation. This is again due to extremely high cooling rates occurring everywhere in the heated area, while for diffusion controlled nucleation, slower cooling rates and longer cooling durations are needed. Although similar phase transformations occur in both regions, the thicknesses of resulting martensitic layers differ significantly. Region 1 possesses a relatively thicker $(\sim 10 \mu \mathrm{m})$ martensitic layer whereas the thickness of martensitic layer in Region 2 is estimated as $2.5 \mu \mathrm{m}$. 
Note that we predicted the phase decomposition after a single laser pulse. Practically, the same domain studied undergoes several heating and cooling cycles during laser processing. Our samples are processed with $5 \mu$ m overlap offset between two consecutive pulses. As can be seen in Fig. 5a, the HAZ extends up to $20 \mu \mathrm{m}$ radius for a single pulse. Therefore, each domain in the processed region experiences heating and cooling cycles during at least 8 consecutive pulses. Although 8 pulses elongate the heating and cooling durations, the thermal processes at a given location do not last long enough for tempering or significant changes in phase decomposition. Therefore, the single pulse analysis presented yields reasonably accurate and comprehensive picture of thermal and microstructural changes that occur during pulsed laser polishing.

\subsection{SEM images}

SEM images of the cross-sections perpendicular to the processed surface are obtained to verify the thermal and microstructural changes presented above. Fig. 7 is taken at a depth of nearly $3 \mathrm{~mm}$ from the processed surface, and thus shows the microstructure of the unprocessed bulk material. As expected, the base material is a mixture of $\alpha$ and $\beta$ phases [48], where $\beta$ phase appears at the boundary of $\alpha$ phase.

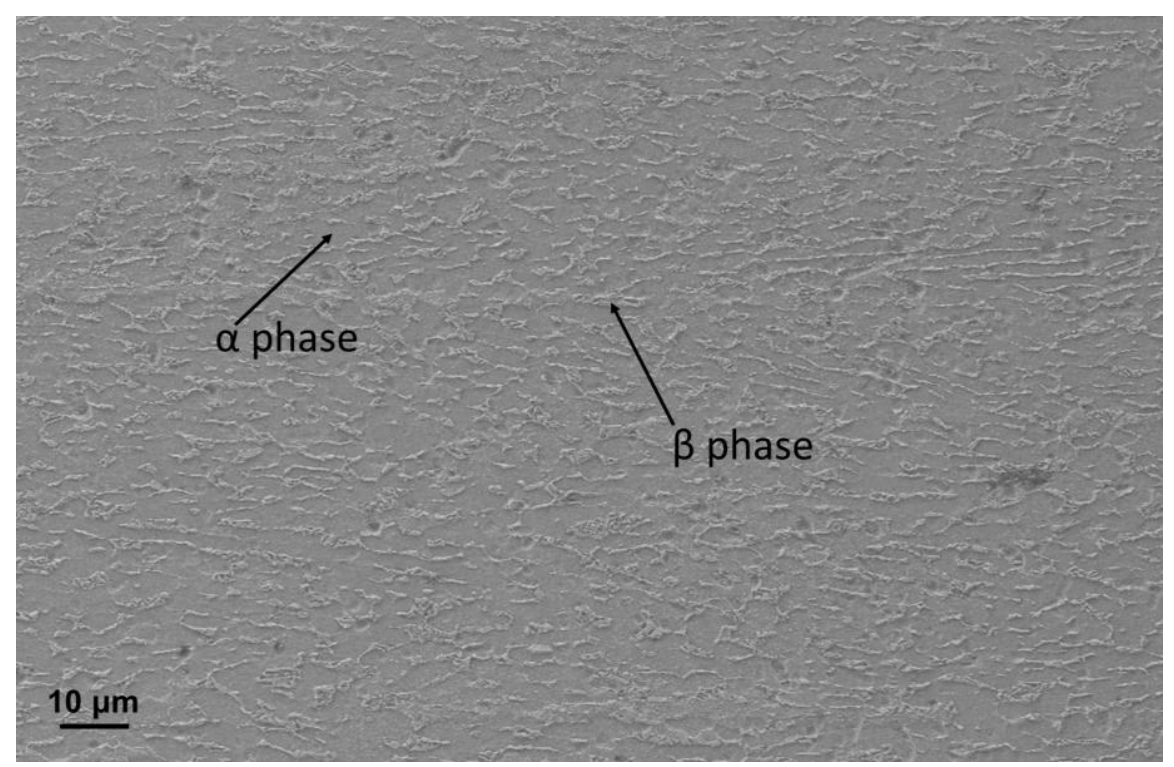

Fig. 7. SEM image of substrate material on the cross section. The material is a two-phase alloy, with $\beta$ phase appearing at the boundary of $\alpha$ phase. 
SEM images of the cross sections of laser processed surfaces are shown in Fig. 8. Some small particles embedded on the cross section might be the remainders of abrasive diamond particles used in polishing. Region 1 with high laser power possesses three distinct layers, namely MZ, HAZ, and bulk material with clear boundaries. The MZ can be recognized easily since there are significant dimples created by laser pulses. The MZ observed in Fig. 8 a reaches up to 3 to $4 \mu \mathrm{m}$ depth. The temperature field we obtain by the FE simulations also predicts the MZ with similar thickness. Moreover, the acicular phase dominates the microstructure in this zone. The acicular phase decreases gradually towards HAZ and disappears at an approximate depth of $10 \mu \mathrm{m}$ while the fraction of $\beta$ phase increases definitely. The volume fraction of $\beta$ phase in deeper part of HAZ is similar to base material, around $10 \%$. These facts are in close agreement with the predicted phase decomposition (Fig. 6). However, at MZ and the upper part of HAZ, no $\beta$ phase remains after laser processing. This observation contradicts with our predictions. Note that our model is based on relatively low heating/cooling rate due to a single pulse; whereas, the surface experiences multiple heating/cooling cycles, with extremely high rates. We suspect that those differences contribute to the discrepancies between the predictions and observations. Region 2 with low laser power does not show a clear MZ. Instead, the material near top surface and the base material are similar. This is in line with our FE simulations, where the MZ depth predicted for Region 2 is sub-micron. Similarly, the phases observed in the SEM image of Region 2 agree with the FE predictions qualitatively. However, SEM image fails to resolve the dominant phases within shallow depths. Similar to Region 1, Region 2 possesses acicular phase in the vicinity of the processed surface as predicted in our FE simulations. Acicular phase coexists with $\alpha$ and $\beta$ phases, and identification of the dominant phases from the SEM image is difficult. 

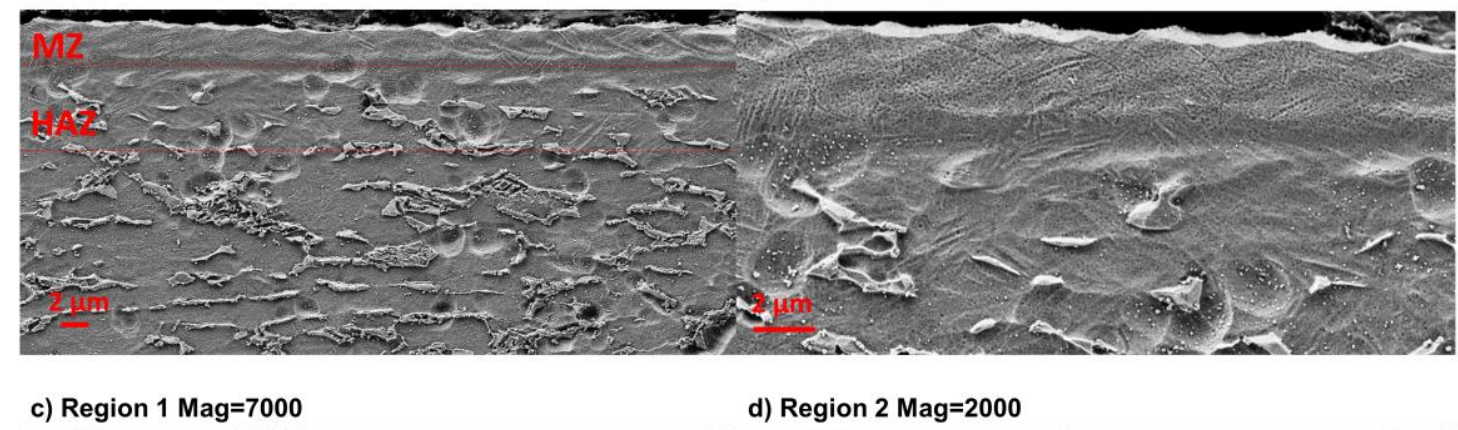

d) Region 2 Mag=2000

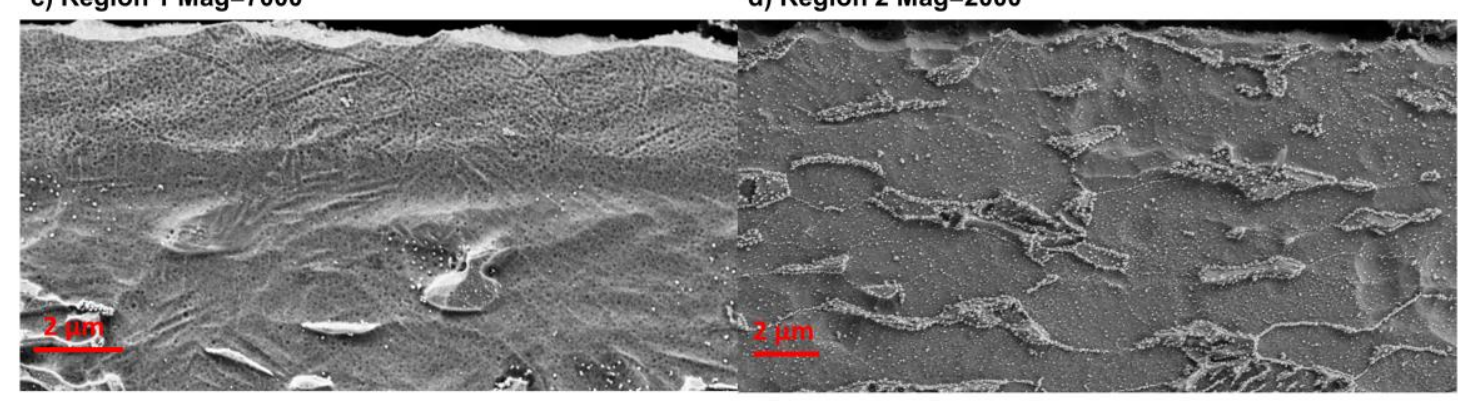

Fig. 8. SEM images of Region 1 and Region 2 cross sections at different magnifications: a) Region 1 at 2000x; b) Region 1 at 5000x; c) Region 1 at 7000x, and d) Region 2 at 2000x. On Region 1, MZ is significant with dimples left by laser pulse, with a depth of 3 to $4 \mu \mathrm{m}$; HAZ is clear with formed acicular phase up to a depth of 9 to $10 \mu \mathrm{m}$. On Region 2, no observable MZ forms after PLP; the region of HAZ is relatively small, and the acicular phase only occurs at the vicinity of processed surface.

\subsection{Hardness map}

Next, we analyze the hardness of the cross sections of Region 1 and 2 by nanoindentation. Fig. 9 shows the hardness obtained at various depths from processed surfaces of both regions (calculated by Eq. (2)). 5 indents per each depth level are conducted on a line parallel to the processed surface. Hardness obtained at each depth are presented as a box plot with upper and lower ends of the box representing 75 and 25 percentiles, respectively. The red lines represent the median values, and red plus sign indicates outliers. The penetration is set to be $200 \mathrm{~nm}$ constantly, thus the radius of the affected area of each indent is approximately $1 \mu \mathrm{m}$. The hardness of one indent is influenced by the material in the range of $2 \mu \mathrm{m}$ centered at the indent. To avoid interactions between consecutive indents, the spacing between two depth levels is set as $3.4 \mu \mathrm{m}$. 

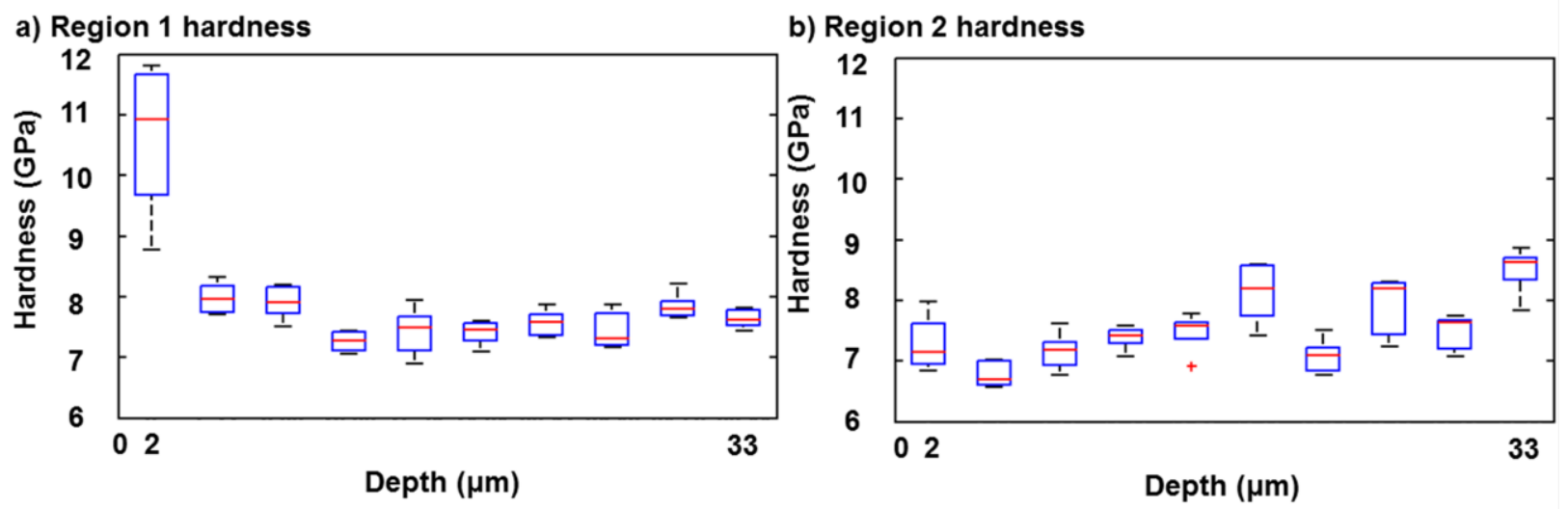

Fig. 9. Nano-Hardness versus depth from a) Region 1, and b) Region 2. The hardness in the vicinity of Region 1 ( 11 GPa) surface is significantly higher than the hardness below $5 \mu \mathrm{m}(\sim 7-8 \mathrm{GPa})$. In contrast, the hardness on the cross-section of Region 2 attains relatively stable values around 7-9 GPa.

On Region 1, the highest hardness occurs near the MZ in the vicinity of the surface. As the depth increases, the hardness decreases and reaches a constant of $7.5 \mathrm{GPa}$. Our FE simulations and SEM analyses predict that the dominant phase near the processed surface of Region 1 is martensitic $\alpha$, with some retaining $\beta$ phase. Since martensitic $\alpha^{\prime}$ is harder than other microstructures [49], high hardness measured near the surface is expected. As the depth increases, the martensitic $\alpha^{\prime}$ phase disappears, and $\alpha$ phase becomes the dominant phase. By the mixture rule, the hardness is expected to drop at the interface between martensitic $\alpha^{\prime}$ phase dominant region and $\alpha$ phase dominant region. The second and the third depth levels from the surface correspond to that interface with immediate hardness reduction. This sudden drop in hardness seems contradicting the phase composition predicted by the FE simulations. The martensitic layer depth is expected to reach up to $9-10 \mu \mathrm{m}$, and so the second depth level would be located within that layer. Low hardness measurements at that location suggest that the volume fraction of martensitic $\alpha^{\prime}$ phase might be lower. Similar discrepancies are observed for Region 2. Specifically, the hardness near the surface of Region 2 is around $7.5 \mathrm{GPa}$ although the predicted dominant phase is martensitic. Those discrepancies in the prediction of martensitic layer thickness and volume fractions might be due to the reaction-rate constant $K$ and Avrami index $n$ used in the phase composition calculations as well as the rough estimation of $\beta$ phase transition during both heating and cooling. $K$ and $n$ 
depend on the temperature, material components and the mechanism of transformation [50-52]. $K$ and $n$ in the current studies are in a temperature range of 1023 to $1223 \mathrm{~K}$. However, in the experiment, the temperature range is up to $3000 \mathrm{~K}$. Besides, super heating and cooling conditions are also known to cause significant changes in transformation parameters and mechanisms [53,54]. The thermal energy deposited by the laser pulses used in our experiments is sufficient to raise the surface temperatures beyond the betatransus temperature, but extreme heating and cooling rates might prevent uniform $\beta$ phase transformation and martensitic transformation. Thus, the martensitic dominant region might be shallower than the calculated equivalent and the volume fraction of $\alpha$ phase would be higher than expected. SEM images with no distinguishable MZ or HAZ, and nearly constant hardness measurement from Region 2 support those complications, which are not modeled in the phase decomposition calculations. A more detailed calculation of phase composition including super heating and cooling effects can explain these deviations. Nevertheless, a thin martensitic layer in the vicinity of processed surface of Region 1 is evident from the calculated phases, and SEM and hardness analyses. This thin layer will be shown to provide wear resistance in the abrasive conditions.

\subsection{Wear Resistance}

The wear properties of both regions are investigated at nano/micro and meso length scales. Fig. 10 shows the nano/microscale wear maps of Region 1 after 1, 10, 50 and 100 passes at the same location. The dashed square at the center is the $20 \times 20 \mu \mathrm{m}$ test location on the processed surface, and the color bars show the surface heights measured by SPM after the given number of passes. As shown in Figure 10, nano/microscale tests on Region 1 accumulate limited wear and scratch marks while most of the tested area remains unaltered even after 100 scratch passes. This indicates superior wear resistance when compared to Region 2. 


\section{a) 1 pass}

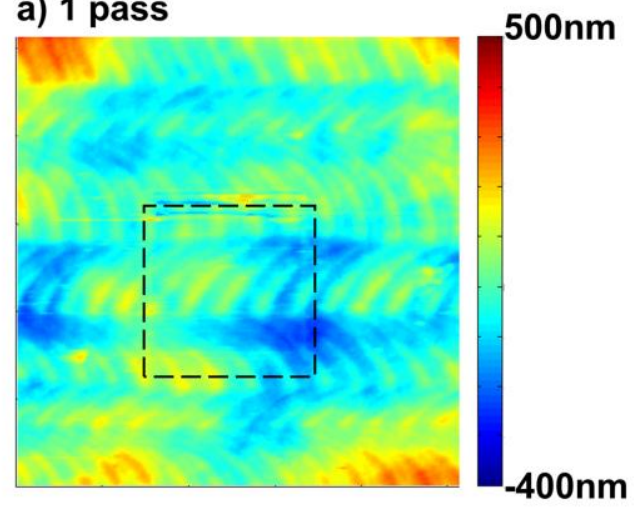

c) 50 passes

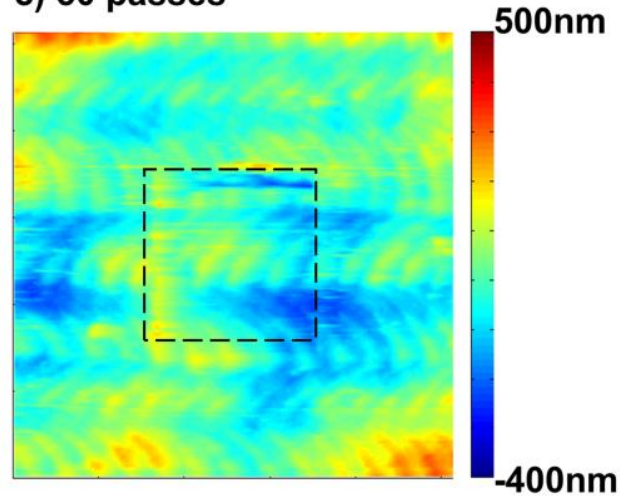

b) 10 passes

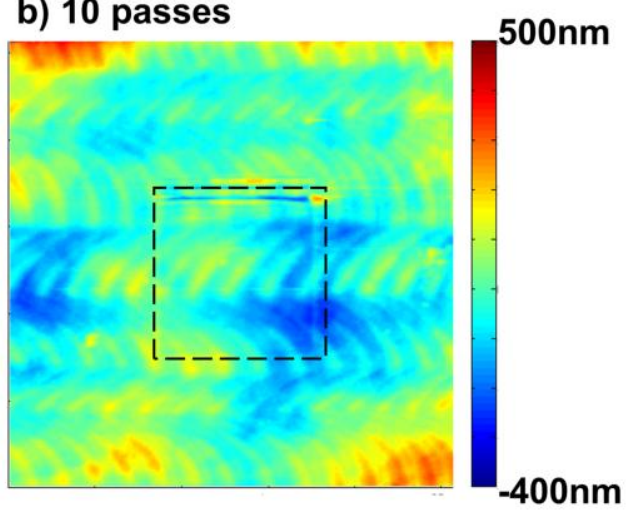

d) 100 passes

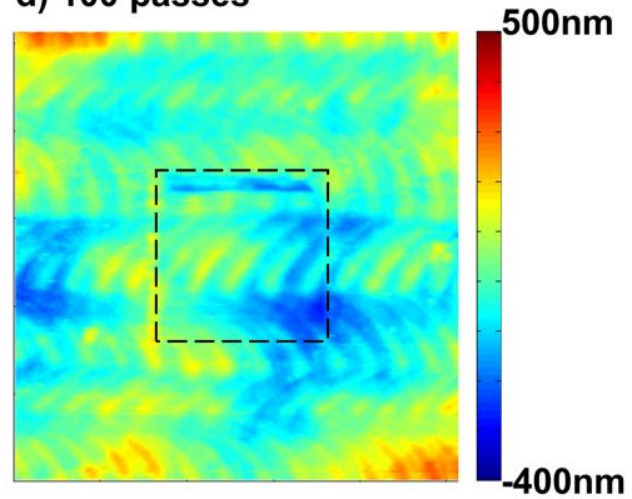

Fig. 10. Wear maps obtained from the surface of Region 1 after a) 1-pass, b) 10-pass, c) 50-pass, and d) 100-pass scratch tests. The dashed square regions represent the tested areas, and color bars show the surface heights. The wear depths don't increase even after 100-pass scratch.

Fig. 11 shows the wear map for Region 2 after 1 and 10 passes. Even after 10 passes significant wear accumulates at the tested area, and wear depth reaches up to $400 \mathrm{~nm}$. This indicates that Region 2 has significantly less wear resistance than Region 1. 
a) 1 pass

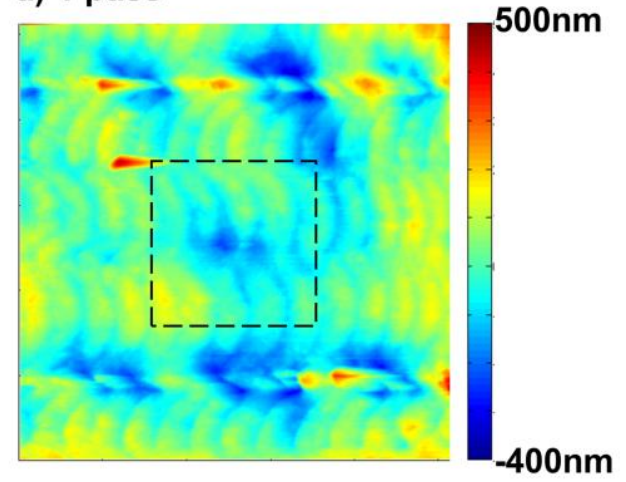

b) 10 pass

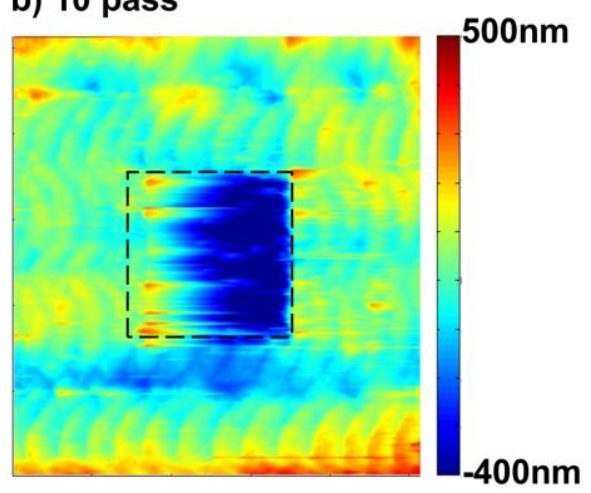

Fig. 11. Wear maps obtained from the surface of Region 2 after a) 1-pass, and b) 10-pass scratch tests. The dashed square regions represent the tested areas, and color bars show the surface heights. The wear depth increases up to $400 \mathrm{~nm}$ after only 10 passes.

Since these wear tests are conducted on the top surfaces, both the roughness and the microstructure of the surfaces will influence the wear resistance. The rms roughness of Region 1 and 2 ranges from 75 to $100 \mathrm{~nm}$ after laser processing. Since those values are comparable, roughness itself cannot explain the significant differences in wear resistance. Therefore, microstructure and phase decomposition should play a critical role in the wear resistance of PLPed surfaces at nano/microscale. As given in Section 2, nano/microscale wear tests are conducted with a cube corner diamond probe with radius $R=40 \mathrm{~nm}$. This probe is pressed on to the surfaces with a normal load of $P=500 \mu \mathrm{N}$. Assuming that the contact is fully plastic, the contact area corresponding to the normal load can be estimated by

$A=\frac{P}{H}$

where $H$ is the hardness of Ti6A14V samples. For an ideal cube-corner probe, the area can be expressed in terms of penetration depth $h$ as

$A=2.598 h^{2}$

Substituting the hardness data of Region 1 and 2 (Fig. 9) as 10.5 and $7.5 \mathrm{GPa}$, respectively in to Eq. (12), we estimate the penetration depths as 135 and $160 \mathrm{~nm}$. Since the wear depths measured in Region 2 are comparable to the probe penetration depths, fully plastic contact assumption holds, and probe wears the 
surface abrasively. Accumulation of further wear depth by increasing number of passes is also expected, since there is a shallower protective layer with dominant martensitic phase. In contrast, the wear depths measured for Region 1 are negligible compared to the initial penetration depths. So, elastic-plastic deformations should be accounted for accurate contact estimation. In any case, the probe penetrates into sub-micron depths, and thus attempts to abrade the martensitic layer of Region 1. Since martensitic phase has considerably higher hardness, scratching this thin layer is more difficult. This in turn explains the improved wear-resistance properties at this scale.

To verify the relative wear resistance of different phases, we obtain 10-pass wear map of the cross section of Region 1, specifically of the square region shown in Fig. 2. Fig. 12 shows the 10x10 $\mu \mathrm{m}$ tested area as the dashed square. The top of the tested area corresponds to the processed surface. As evident from the wear map, the wear depth is small close to the surface, and increases deeper into the surface. The wear map correlates qualitatively with the phase decomposition map shown in Fig. 6a; suggesting that a 4-5 $\mu \mathrm{m}$ martensitic layer close to the surface provides the wear resistance while the rest of the HAZ shows poor wear properties as in Region 2. The thickness of the protective martensitic layer correlates quantitatively with the hardness measurements, but differs significantly from the predicted thickness of 9$10 \mu \mathrm{m}$. As discussed above, the transformation parameters and mechanisms assumed in the calculations are the possible causes of this mismatch.

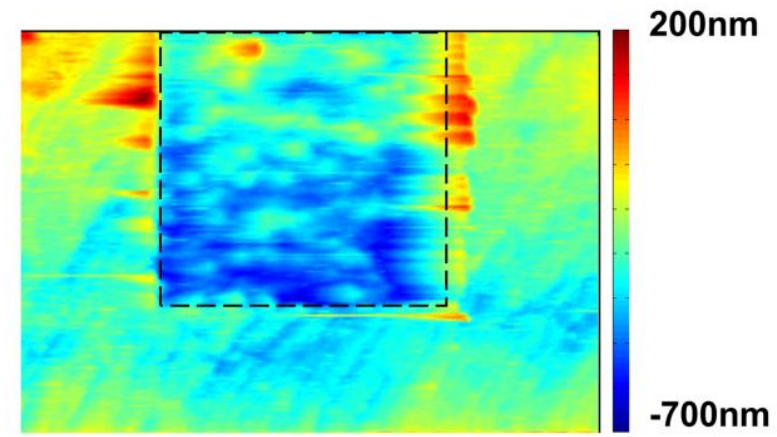

Fig. 12. Wear map obtained from the cross section of Region 1 after 10 passes. The dashed square region represents the tested areas, and color bar shows the surface heights. The wear depth is small close to the laser processed surface, and increases away from the surface. 
Finally, mesoscale wear tests are performed on the processed surfaces of both regions to check if the nano/microscale wear properties hold for application scales. The wear tracks are characterized under optical microscope at 5x magnification rate. As shown in Fig. 13, the probe is slid perpendicular to the undulations caused by the laser pulses, under two normal loads and for 2000 cycles. On Region 1, the resulting wear tracks under both loads are in the shape of straight thin lines with constant width, and the track depths are rather small. On Region 2, the wear tracks suggest significantly severer wear characterized by wider wear tracks with irregular outer profiles. Fig. 14 shows the resulting line profiles of the middle portion of wear tracks on Region 1 and 2 under $1 \mathrm{~N}$ load. The maximum depth and width of the wear track on Region 1 are 1 and $15 \mu \mathrm{m}$, respectively. For Region 2, those values increase up to 8 and $75 \mu \mathrm{m}$. Note that even with $1 \mu \mathrm{m}$ of wear depth of Region 1 , the probe at mesoscale still abrades the protective martensitic layer. However, Region 2 experiences excessive wear, and wear properties as poor as the bulk state since $8 \mu \mathrm{m}$ wear depth is even more than the over-predicted martensitic layer thickness. 

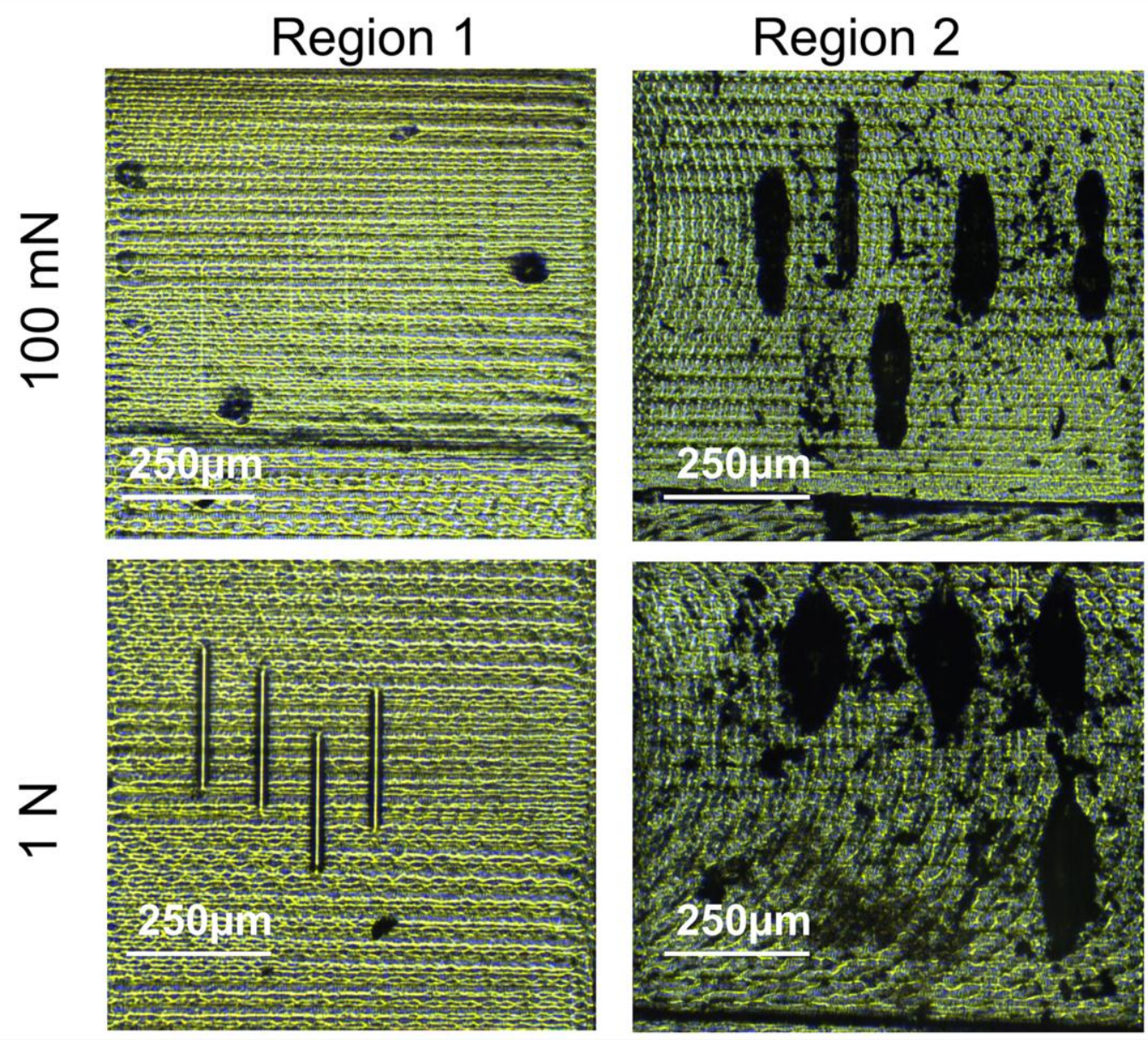

Fig. 13. Optical microscope images of 4 wear tracks formed under $100 \mathrm{mN}$ and $1 \mathrm{~N}$ on Region 1 and Region 2. On Region 1, the wear tracks are straight thin lines with constant width, and the wear depths are small. On Region 2, the wear tracks suggest severer wear characterized by wider and irregular wear tracks.

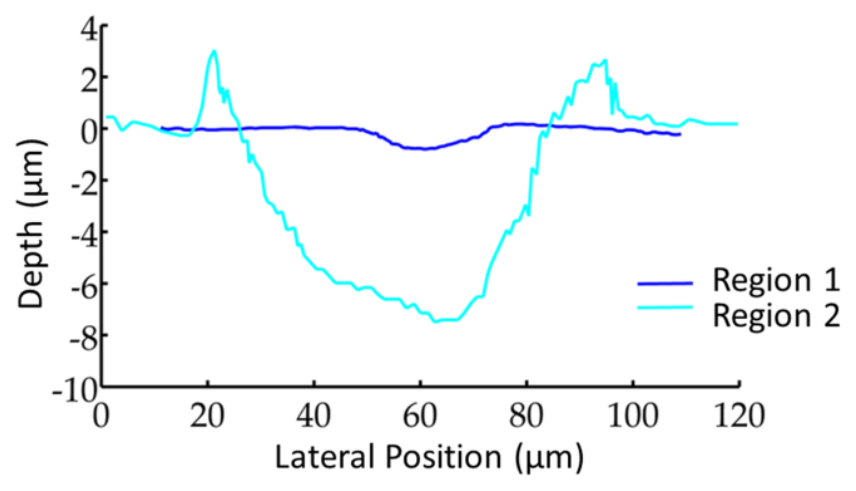

Fig. 14. Cross sectional profiles of wear tracks formed at $1 \mathrm{~N}$ normal force. The maximum depth and width of the wear track on Region 1 are 1 and $15 \mu \mathrm{m}$, respectively. For Region 2, the depth and width values increase to 8 and $75 \mu \mathrm{m}$. 
The results of both nano/micro and mesoscale wear tests show that under the same loading condition, abrasive wear resistance of Region 1 is significantly higher than Region 2. From the mesoscale wear test results (Fig. 14 and Fig. 15), the wear behaviors of base material and Region 2 are similar, with an ultimate wear depth of approximately 6 to $8 \mu \mathrm{m}$, whereas Region1 shows an excellent wear resistance with a wear depth within $1 \mu \mathrm{m}$. Note that the wear resistance will increase with increasing hardness [55]. Nevertheless, the underlying reason of significant improvement in wear resistance of Region 1 is the microstructural changes induced by laser processing. The predicted dominant phase on Region 1 surface is martensitic $\alpha^{\prime}$ and the hardness is highest in this area, thus the wear resistance is improved significantly. Literature also shows that the martensitic Ti6A14V ELI alloys has the highest hardness and wear resistance among other phases [49]. The microstructure of Region 2 surface doesn't change significantly compared to initial phases, since only a small amount of acicular phase forms after low power heating. The hardness of Region 2 stays the same with the base material regardless of depth from the processed surface. Hence, Region 2 shows a similar wear behavior as base material.

However, hardness is not the only reason to the improvement of wear resistance at mesoscale because the abrasive wear needs to stop approximately when the maximum contact pressure decreases below yield strength, and this corresponds to sub-micron wear depths for both regions. Measured wear depths are significantly larger than those threshold depths. To investigate this further, we study the evolution of mean penetration depths obtained from wear tests under $1 \mathrm{~N}$ normal load. These depths can be assumed as a measure of wear depth. Fig. 15 shows that the wear depths on Region 1 change very negligibly compared to Region 2 and base material. All tests on Region 2 and base material follow a similar evolution pattern yielding final wear depths of 6-8 um. The irregular evolution pattern for all of the tests suggests the wear particles and irregular surface patterns entrapped in the wear track. These particles and irregularities themselves cause stress concentrations, and further accumulation of wear. In other words, the continuous contact assumption used in pressure estimations fails to hold for Region 2 and base material. 


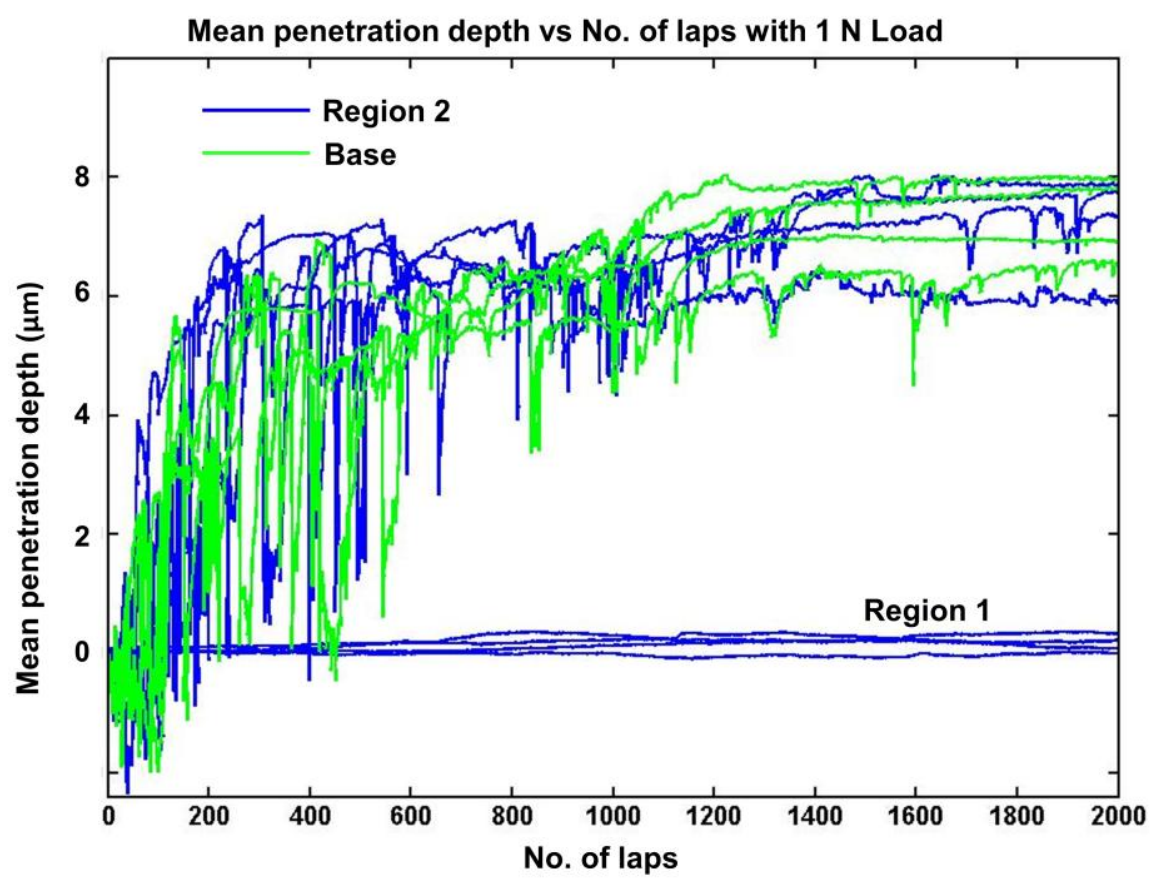

Fig. 15. Mean penetration depths versus number of laps on Region 1, Region 2, and base material at 1 N. On Region 1, the mean penetration depth representative of wear stay at low values $(<1 \mu \mathrm{m})$ stably over 2000 wear laps. On Region 2 and base material, in contrast, the mean penetration depths increase fast to values of 6-8 $\mu \mathrm{m}$.

Another reason of excessive wear accumulation at mesoscale might be low cycle fatigue. For Ti6Al4V, low cycle fatigue strength will improve with increasing cooling rate because of reduction in grain size [48]. In mesoscale test, the scratch track length is $250 \mu \mathrm{m}$, which will cover multiple grains on the surface. The size of these grains will influence the fatigue strength. Smaller grain sizes also lead to higher fracture toughness [34]. Higher heat input causes higher cooling rates in PLP, and thus Region 1 is expected to possess smaller grains than Region 2. This in turn can contribute to the fatigue and wear resistance in cyclic loading conditions. However, it is difficult to polish and etch the surface without damaging the thin layer processed by PLP, especially on Region 2. Therefore, the characterization of surface grain size is not trivial. Martensitic layer confined to the processed surface, however, possesses higher hardness and lower fracture toughness. So, the brittle martensitic layer and the grain refinement need to be optimized on laser-processed surfaces for improved wear resistance. In this respect, PLP offers 
a better method of surface processing than traditional continuous laser polishing, which forms thick martensitic layers.

\section{Conclusions}

In this work, we study the microstructure and mechanical properties of Ti6Al4V surfaces processed by pulsed lasers with high and low power settings. We first use a finite element model to obtain thermal changes induced by a single laser pulse. Then, we estimate the composition, volume fractions and distribution of phases after PLP by plugging in the thermal history into JMA equations. We conduct a series of experiments, including SEM characterization, nanoindentation, wear tests at nano/micro and meso length scales, to investigate the relation between the microstructural morphology and mechanical properties. We find that:

1) The processed region can be divided into 3 layers depending on the thermal history: MZ, HAZ and bulk material. At low laser power, $\mathrm{MZ}$ is undetectable.

2) The intense heat input of pulsed laser processing leads to concentrated martensite in the vicinity of processed surface, and the rest of the material is unaltered.

3) The phase evolution results in an alteration of hardness and wear resistance. The experimental results are in good agreement with the predicted phase constitution qualitatively.

4) High laser power leads to a thin and protective surface layer consisting of acicular martensitic phase and a small portion of retaining $\beta$ phase. The surface shows a higher hardness, and superior wear resistance at both nano/micro and mesoscales.

5) Low laser power is not sufficient to form a martensitic layer; thus the hardness and wear resistance are not improved when compared to bulk material.

6) Adjusting the pulsed laser power and thus the microstructural evolution determine the thickness of the protective martensitic layer and control grain refinement. This process parameter can be altered to achieve an optimum balance between hardness and ductility that improves wear resistance across multiple length scales. 
In summary, PLP is an effective method to improve the wear behavior of Ti6Al4V surfaces. By this method, the mechanical properties can be controlled without influencing the bulk material.

\section{Acknowledgment}

This work is supported by the National Science Foundation under Grant No. NSF-CMMI-1462295.

Nomenclature

$\begin{array}{cl}I_{\alpha} & \text { Intensity of } \alpha \text { phase } \\ I_{\beta} & \text { Intensity of } \beta \text { phase } \\ A_{0} & \text { Constant to calculate phase volume fraction, 1.672 } \\ H & \text { Hardness } \\ P_{\text {max }} & \text { Maximum load in nanoindentation } \\ \rho & \text { Density } \\ c_{p} & \text { Sensible specific heat } \\ c_{p}{ }^{\prime} & \text { Equivalent specific heat } \\ f_{l} & \text { Liquid fraction } \\ T & \text { Temperature } \\ t & \text { Time } \\ \vec{u} & \text { Fluid flow velocity } \\ K & \text { Thermal conductivity } \\ L & \text { Specific latent heat } \\ P_{a v g} & \text { Heat flux } \\ \alpha & \text { Absorption rate, } 0.5 \\ P_{a b s} & \text { Absorbed laser power } \\ t_{p u l s e} & \text { Ruration }\end{array}$




$\begin{array}{cl}D C & \text { Duty cycle, } 20 \% \\ f_{\alpha}(t) & \text { Volume fraction of } \alpha \\ f_{\alpha}^{i n i} & \text { Initial volume fraction of } \alpha \text { phase } \\ K & \text { Reaction rate constant } \\ n & \text { Avrami index } \\ f_{\alpha}^{r e m} & \text { Volume fraction of } \alpha \text { after heating } \\ \delta & \text { Penetration depth in nanoindentation } \\ a & \text { Radius of contact circle } \\ R_{0} & \text { Combined radius of probe } \\ E^{*} & \text { Combined elastic modulus } \\ P & \text { Load in nanoindentation } \\ h & \text { Penetration depth } \\ Y & \text { Yield strength } \\ V & \text { Scanning velocity }\end{array}$




\section{Appendix}

Temperature-dependent parameters used in COMSOL [29,56]:

(a) Thermo Conductivity

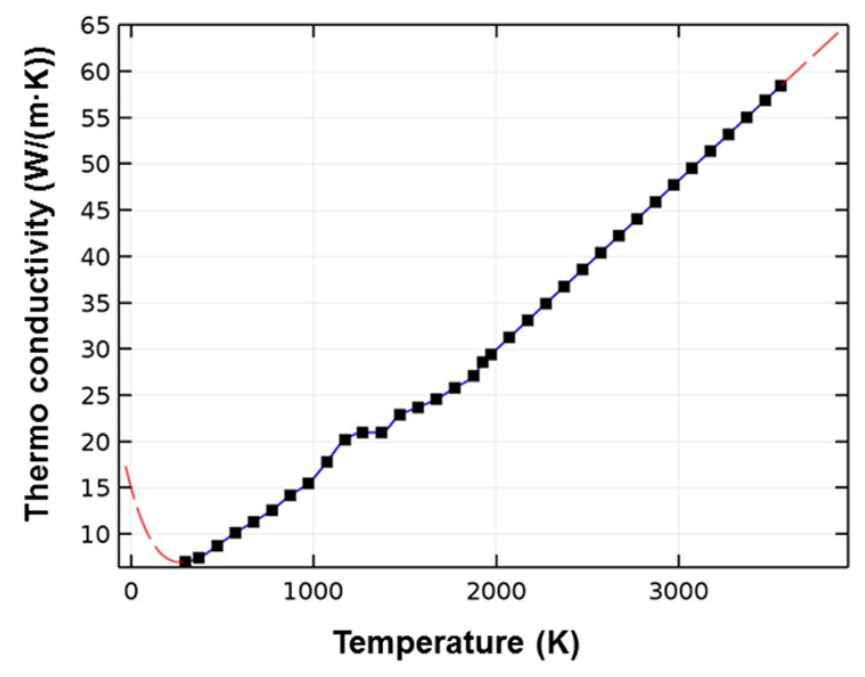

(b) Specific heat

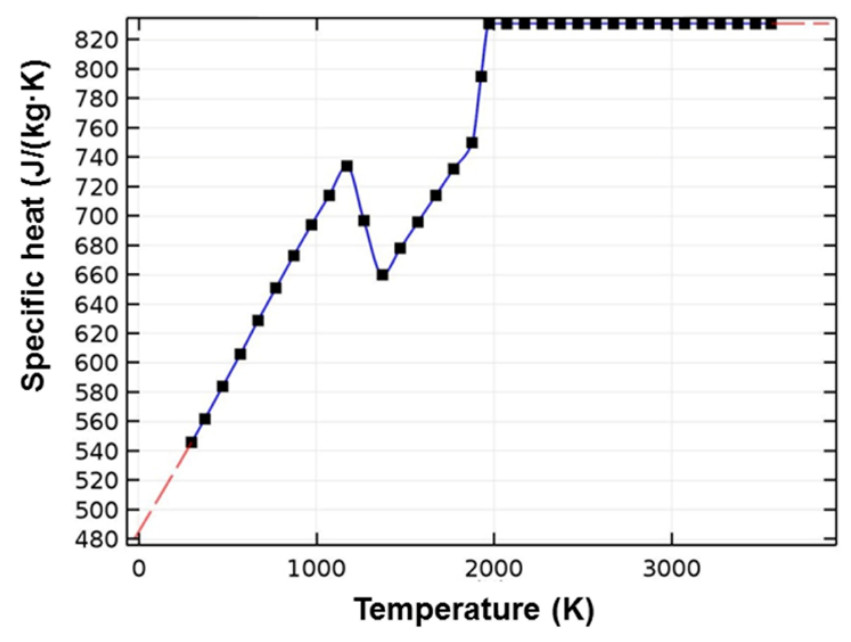




\section{References}

[1] L. Ceschini, E. Lanzoni, C. Martini, D. Prandstraller, G. Sambogna, Comparison of dry sliding friction and wear of Ti6Al4V alloy treated by plasma electrolytic oxidation and PVD coating, Wear. 264 (2008) 86-95. doi:10.1016/j.wear.2007.01.045.

[2] C. Pierret, L. Maunoury, I. Monnet, S. Bouffard, A. Benyagoub, C. Grygiel, D. Busardo, D. Muller, D. Höche, Friction and wear properties modification of Ti-6Al-4V alloy surfaces by implantation of multi-charged carbon ions, Wear. 319 (2014) 19-26. doi:10.1016/j.wear.2014.07.001.

[3] M. Duraiselvam, A. Valarmathi, S.M. Shariff, G. Padmanabham, Laser surface nitrided Ti-6Al-4V for light weight automobile disk brake rotor application, Wear. 309 (2014) 269-274. doi:10.1016/j.wear.2013.11.025.

[4] H.J. Rack, J.I. Qazi, Titanium alloys for biomedical applications, Materials Science and Engineering: C. 26 (2006) 1269-1277. doi:10.1016/j.msec.2005.08.032.

[5] P. Sioshansi, R.W. Oliver, F.D. Matthews, Wear improvement of surgical titanium alloys by ion implantation, Journal of Vacuum Science \& Technology A. 3 (1985) 2670-2674. doi:10.1116/1.572811.

[6] X.D. Zhang, S.Z. Hao, X.N. Li, C. Dong, T. Grosdidier, Surface modification of pure titanium by pulsed electron beam, Applied Surface Science. 257 (2011) 5899-5902. doi:10.1016/j.apsusc.2011.01.136.

[7] P. Jiang, X.L. He, X.X. Li, L.G. Yu, H.M. Wang, Wear resistance of a laser surface alloyed Ti-6Al-4V alloy, Surface and Coatings Technology. 130 (2000) 24-28. doi:10.1016/S0257-8972(00)00680-0.

[8] M. Guemmaz, A. Mosser, L. Boudoukha, J.J. Grob, D. Raiser, J.C. Sens, Ion beam synthesis of nonstoichiometric titanium carbide: composition structure and nanoindentation studies, Nuclear Instruments and Methods in Physics Research Section B: Beam Interactions with Materials and Atoms. 111 (1996) 263-270. doi:10.1016/0168-583X(95)01461-6.

[9] B. Rauschenbach, Mechanical properties of nitrogen ion-implanted Ti-6Al-4V alloy, Surface and Coatings Technology. 66 (1994) 279-282. doi:10.1016/0257-8972(94)90012-4.

[10] X. Liu, P.K. Chu, C. Ding, Surface modification of titanium, titanium alloys, and related materials for biomedical applications, Materials Science and Engineering: R: Reports. 47 (2004) 49-121. doi:10.1016/j.mser.2004.11.001.

[11] Y. Fan, P. Cheng, Y.L. Yao, Z. Yang, K. Egland, Effect of phase transformations on laser forming of Ti-6Al-4V alloy, Journal of Applied Physics. 98 (2005) 013518. doi:10.1063/1.1944202.

[12] E. Akman, A. Demir, T. Canel, T. Sınmazçelik, Laser welding of Ti6Al4V titanium alloys, Journal of Materials Processing Technology. 209 (2009) 3705-3713. doi:10.1016/j.jmatprotec.2008.08.026.

[13] V.K. Balla, J. Soderlind, S. Bose, A. Bandyopadhyay, Microstructure, mechanical and wear properties of laser surface melted Ti6Al4V alloy, Journal of the Mechanical Behavior of Biomedical Materials. 32 (2014) 335-344. doi:10.1016/j.jmbbm.2013.12.001.

[14] J.L. Xiao-Long Gao, Effect of the overlapping factor on the microstructure and mechanical properties of pulsed Nd:YAG laser welded Ti6Al4V sheets, Materials Characterization. 93 (2014). doi:10.1016/j.matchar.2014.04.005.

[15] S. Suresh, Y. Sugimura, T. Ogawa, Fatigue cracking in materials with brittle surface coatings, Scripta Metallurgica et Materialia. 29 (1993) 237-242. doi:10.1016/0956-716X(93)90315-J.

[16] D. Höche, G. Rapin, P. Schaaf, FEM simulation of the laser plasma interaction during laser nitriding of titanium, Applied Surface Science. 254 (2007) 888-892. doi:10.1016/j.apsusc.2007.08.079.

[17] D. Höche, M. Shinn, J. Kaspar, G. Rapin, P. Schaaf, Laser pulse structure dependent texture of FEL synthesized TiN x coatings, J. Phys. D: Appl. Phys. 40 (2007) 818. doi:10.1088/0022-3727/40/3/019. 
[18] T.L. Perry, D. Werschmoeller, X. Li, F.E. Pfefferkorn, N.A. Duffie, Pulsed laser polishing of micromilled Ti6Al4V samples, Journal of Manufacturing Processes. 11 (2009) 74-81. doi:10.1016/j.jmapro.2009.10.001.

[19] M.S. Brown, C.B. Arnold, Fundamentals of Laser-Material Interaction and Application to Multiscale Surface Modification, in: K. Sugioka, M. Meunier, A. Piqué (Eds.), Laser Precision Microfabrication, Springer Berlin Heidelberg, 2010: pp. 91-120. http://link.springer.com/chapter/10.1007/978-3642-10523-4_4 (accessed April 18, 2016).

[20] F.E. Pfefferkorn, N.A. Duffie, X. Li, M. Vadali, C. Ma, Improving surface finish in pulsed laser micro polishing using thermocapillary flow, CIRP Annals - Manufacturing Technology. 62 (2013) 203-206. doi:10.1016/j.cirp.2013.03.112.

[21] K. Kato, Wear in relation to friction - a review, Wear. 241 (2000) 151-157. doi:10.1016/S00431648(00)00382-3.

[22] S.J. Bull, P.R. Chalker, C. Johnston, V. Moore, The effect of roughness on the friction and wear of diamond thin films, Surface and Coatings Technology. 68-69 (1994) 603-610. doi:10.1016/02578972(94)90224-0.

[23] J.D. Morrow, Q. Wang, N.A. Duffie, F.E. Pfefferkorn, Effects of Pulsed Laser Micro Polishing on Microstructure and Mechanical Properties of S7 Tool Steel, (2014). http://digital.library.wisc.edu/1793/68778.

[24] L. Chai, B. Chen, S. Wang, N. Guo, C. Huang, Z. Zhou, W. Huang, Microstructural changes of Zr702 induced by pulsed laser surface treatment, Applied Surface Science. 364 (2016) 61-68. doi:10.1016/j.apsusc.2015.12.105.

[25] H. Kotan, IN-SITU AND EX-SITU PULSED LASER MELTING AND RAPID LATERAL SOLIDIFICATION OF AI THIN FILMS, (2010). http://d-scholarship.pitt.edu/6778/ (accessed March 27, 2016).

[26] Y. Guan, W. Zhou, H. Zheng, M. Hong, Y. Zhu, B. Qi, Effect of pulse duration on heat transfer and solidification development in laser-melt magnesium alloy, Appl. Phys. A. 119 (2015) 437-442. doi:10.1007/s00339-015-9105-4.

[27] N. Yasavol, A. Abdollah-zadeh, M. Ganjali, S.A. Alidokht, Microstructure and mechanical behavior of pulsed laser surface melted AISI D2 cold work tool steel, Applied Surface Science. 265 (2013) 653-662. doi:10.1016/j.apsusc.2012.11.070.

[28] P.S. Mohanty, J. Mazumder, Solidification behavior and microstructural evolution during laser beam - material interaction, Metall and Materi Trans B. 29 (1998) 1269-1279. doi:10.1007/s11663-998-0050-x.

[29] C. Ma, M. Vadali, N.A. Duffie, F.E. Pfefferkorn, X. Li, Melt Pool Flow and Surface Evolution During Pulsed Laser Micro Polishing of Ti6Al4V, J. Manuf. Sci. Eng. 135 (2013) 061023-061023. doi:10.1115/1.4025819.

[30] S. Malinov, P. Markovsky, W. Sha, Z. Guo, Resistivity study and computer modelling of the isothermal transformation kinetics of Ti-6Al-4V and Ti-6Al-2Sn-4Zr-2Mo-0.08Si alloys, Journal of Alloys and Compounds. 314 (2001) 181-192. doi:10.1016/S0925-8388(00)01227-5.

[31] S. Yerramareddy, S. Bahadur, Effect of operational variables, microstructure and mechanical properties on the erosion of Ti-6Al-4V, Wear. 142 (1991) 253-263. doi:10.1016/00431648(91)90168-T.

[32] L.T. Bey Vrancken, Heat treatment of Ti6Al4V produced by Selective Laser Melting: Microstructure and Mechanical properties, Journal of Alloys and Compounds. 541 (2012) 177-185. doi:10.1016/j.jallcom.2012.07.022.

[33] G. Lütjering, Influence of processing on microstructure and mechanical properties of $(\alpha+\beta)$ titanium alloys, Materials Science and Engineering: A. 243 (1998) 32-45. doi:10.1016/S09215093(97)00778-8. 
[34] R. Pederson, Microstructure and phase transformation of Ti-6Al-4V, Licentiate Thesis, Lulea University of Technology, 2002. http://epubl.luth.se/1402-1757/2002/30/index-en.html (accessed March 21, 2016).

[35] M.T. Jovanović, S. Tadić, S. Zec, Z. Mišković, I. Bobić, The effect of annealing temperatures and cooling rates on microstructure and mechanical properties of investment cast Ti-6Al-4V alloy, Materials \& Design. 27 (2006) 192-199. doi:10.1016/j.matdes.2004.10.017.

[36] J.W. Elmer, T.A. Palmer, S.S. Babu, W. Zhang, T. Debroy, Direct Observations of Phase Transitions in Ti6Al4V Alloy Transient Welds using Time Resolved X-Ray Diffraction, Journal of Applied Physics. (2003).

https://www.researchgate.net/publication/255200511_Direct_Observations_of_Phase_Transition s_in_Ti6Al4V_Alloy_Transient_Welds_using_Time_Resolved_X-Ray_Diffraction (accessed March $18,2016)$.

[37] J.W. Elmer, T.A. Palmer, S.S. Babu, E.D. Specht, In situ observations of lattice expansion and transformation rates of $\alpha$ and $\beta$ phases in Ti-6Al-4V, Materials Science and Engineering: A. 391 (2005) 104-113. doi:10.1016/j.msea.2004.08.084.

[38] W. c. Oliver, G. m. Pharr, An improved technique for determining hardness and elastic modulus using load and displacement sensing indentation experiments, Journal of Materials Research. 7 (1992) 1564-1583. doi:10.1557/JMR.1992.1564.

[39] C. Ma, M. Vadali, X. Li, N.A. Duffie, F.E. Pfefferkorn, Analytical and Experimental Investigation of Thermocapillary Flow in Pulsed Laser Micropolishing, J. Micro Nano-Manuf. 2 (2014) 021010021010. doi:10.1115/1.4027433.

[40] K.C. Mills, National Physical Laboratory (Grande Bretagne), Recommended values of thermophysical properties for selected commercial alloys, Materials Park, Ohio : Woodhead ;, Cambridge; ASM International, 2002. http://www.knovel.com/knovel2/Toc.jsp?BookID=870 (accessed March 19, 2016).

[41] T. Ahmed, H.J. Rack, Phase transformations during cooling in $\alpha+\beta$ titanium alloys, Materials Science and Engineering: A. 243 (1998) 206-211. doi:10.1016/S0921-5093(97)00802-2.

[42] M. Majdic, G. Ziegler, Effect of the Metastable beta-Phase Transformations in the Ti-6Al-4V Alloy, Zeitschrift Fuer Metallkunde/Materials Research and Advanced Techniques. 64 (1973) 751-758.

[43] R. Pederson, O. Babushkin, F. Skystedt, R. Warren, Use of high temperature X-ray diffractometry to study phase transitions and thermal expansion properties in Ti-6Al-4V, Materials Science and Technology. 19 (2003) 1533-1538. doi:10.1179/026708303225008013.

[44] J.W. Elmer, T.A. Palmer, S.S. Babu, W. Zhang, T. DebRoy, Phase transformation dynamics during welding of Ti-6Al-4V, Journal of Applied Physics. 95 (2004) 8327-8339. doi:10.1063/1.1737476.

[45] W. Sha, Z. Guo, Phase evolution of Ti-6Al-4V during continuous heating, Journal of Alloys and Compounds. 290 (1999) L3-L7. doi:10.1016/S0925-8388(99)00199-1.

[46] S. Malinov, Z. Guo, W. Sha, A. Wilson, Differential scanning calorimetry study and computer modeling of $\beta \Rightarrow \alpha$ phase transformation in a Ti-6Al-4V alloy, Metall and Mat Trans A. 32 (2001) 879-887. doi:10.1007/s11661-001-0345-x.

[47] W. Steen, J. Mazumder, Laser Material Processing, Springer Science \& Business Media, 2010.

[48] V.K. Balla, J. Soderlind, S. Bose, A. Bandyopadhyay, Microstructure, mechanical and wear properties of laser surface melted Ti6Al4V alloy, Journal of the Mechanical Behavior of Biomedical Materials. 32 (2014) 335-344. doi:10.1016/j.jmbbm.2013.12.001.

[49] I. Cvijović-Alagić, Z. Cvijović, S. Mitrović, V. Panić, M. Rakin, Wear and corrosion behaviour of Ti$13 \mathrm{Nb}-13 \mathrm{Zr}$ and Ti-6Al-4V alloys in simulated physiological solution, Corrosion Science. 53 (2011) 796-808. doi:10.1016/j.corsci.2010.11.014.

[50] H.E. Atyia, A.S. Farid, Non-isothermal crystallization kinetics of ternary Se90Te10-xPbx glasses, Journal of Crystal Growth. 436 (2016) 125-133. doi:10.1016/j.jcrysgro.2015.12.004. 
[51] Y.B. Tan, L.H. Yang, J.L. Duan, L.Y. Ji, W.C. Liu, Studies on the kinetics of $\beta \rightarrow \alpha$ phase transformation in 47Zr-45Ti-5Al-3V alloy under isothermal conditions by $\mathrm{X}$-ray diffraction, Materials Characterization. 112 (2016) 98-104. doi:10.1016/j.matchar.2015.12.010.

[52] G. Štrbac, D. Štrbac, S. Lukić-Petrović, M. Šiljegović, Thermal characterization of glasses from FeSb-S-I system, J Therm Anal Calorim. (2016) 1-8. doi:10.1007/s10973-016-5382-1.

[53] S.-N. Luo, L. Zheng, A. Strachan, D.C. Swift, Melting dynamics of superheated argon: Nucleation and growth, The Journal of Chemical Physics. 126 (2007) 034505. doi:10.1063/1.2424715.

[54] L. Zheng, Q. An, Y. Xie, Z. Sun, S.-N. Luo, Homogeneous nucleation and growth of melt in copper, The Journal of Chemical Physics. 127 (2007) 164503. doi:10.1063/1.2790424.

[55] M.M. Khruschov, Principles of abrasive wear, Wear. 28 (1974) 69-88. doi:10.1016/00431648(74)90102-1.

[56] R. Rai, J.W. Elmer, T.A. Palmer, T. DebRoy, Heat transfer and fluid flow during keyhole mode laser welding of tantalum, Ti-6Al-4V, 304L stainless steel and vanadium, J. Phys. D: Appl. Phys. 40 (2007) 5753. doi:10.1088/0022-3727/40/18/037. 